\title{
(2) OPEN ACCESS \\ Hyperbaric oxygen as an adjuvant treatment for patients with COVID-19 severe hypoxaemia: a randomised controlled trial
}

\author{
Mariana Cannellotto, ${ }^{1}$ Mariano Duarte, ${ }^{2,3}$ Guillermo Keller (1) , ${ }^{4,5,6}$ Ramiro Larrea, \\ Eleonora Cunto, ${ }^{8}$ Viviana Chediack, ${ }^{8}$ Mariela Mansur, ${ }^{7}$ Daniela M Brito, ${ }^{7}$ \\ Elizabeth García, ${ }^{5}$ Héctor E Di Salvo, ${ }^{5}$ Fabrizio Verdini, ${ }^{1}$ Cecilia Domínguez, ${ }^{8}$ \\ Liliana Jorda-Vargas, ${ }^{1}$ Javier Roberti @ 9,10 Guillermo Di Girolamo, ${ }^{4,6}$ \\ Esteban Estrada ${ }^{1,11}$
}

Handling editor Lara Nicole Goldstein

For numbered affiliations see end of article.

Correspondence to Dr Javier Roberti, Institute for Clinical Effectiveness and Health Policy, Buenos Aires, Argentina; javierroberti@gmail.com

Received 1 February 2021 Accepted 14 October 2021 Published Online First 14 December 2021

\section{Linked}

- http://dx.doi.org/10.1136/ emermed-2021-212015

Check for updates

(C) Author(s) (or their employer(s)) 2022. Re-use permitted under CC BY-NC. No commercial re-use. See rights and permissions. Published by BMJ.

To cite: Cannellotto $\mathrm{M}$,

Duarte M, Keller G,

et al. Emerg Med J

2022;39:88-93.

\section{ABSTRACT}

Background Hyperbaric oxygen $\left(\mathrm{HBO}_{2}\right)$ therapy

has been proposed to treat hypoxaemia and reduce inflammation in COVID-19. Our objective was to analyse safety and efficacy of $\mathrm{HBO}_{2}$ in treatment of hypoxaemia in patients with COVID-19 and evaluate time to hypoxaemia correction.

Methods This was a multicentre, open-label randomised controlled trial conducted in Buenos Aires, Argentina, between July and November 2020. Patients with COVID-19 and severe hypoxaemia $\left(\mathrm{SpO}_{2} \leq 90 \%\right.$ despite oxygen supplementation) were assigned to receive either $\mathrm{HBO}_{2}$ treatment or the standard treatment for respiratory symptoms for 7 days. $\mathrm{HBO}_{2}$ treatment was planned for $\geq 5$ sessions ( 1 /day) for $90 \mathrm{~min}$ at 1.45 atmosphere absolute (ATA). Outcomes were time to normalise oxygen requirement to $\mathrm{SpO}_{2} \geq 93 \%$, need for mechanical respiratory assistance, development of acute respiratory distress syndrome and mortality within 30 days. A sample size of 80 patients was estimated, with a planned interim analysis after determining outcomes on $50 \%$ of patients.

Results The trial was stopped after the interim analysis. 40 patients were randomised, 20 in each group, age was $55.2 \pm 9.2$ years. At admission, frequent symptoms were dyspnoea, fever and odynophagia; $\mathrm{SpO}_{2}$ was $85.1 \% \pm 4.3 \%$ for the whole group. Patients in the treatment group received an average of $6.2 \pm 1.2 \mathrm{HBO}_{2}$ sessions. Time to correct hypoxaemia was shorter in treatment group versus control group; median 3 days (IQR 1.0-4.5) versus median 9 days (IQR 5.5-12.5), respectively $(p<0.010)$. OR for recovery from hypoxaemia in the $\mathrm{HBO}_{2}$ group at day 3 compared with the control group was 23.2 (95\% Cl 1.6 to $329.6 ; p=0.001$ ) Treatment had no statistically significant effect on acute respiratory distress syndrome, mechanical ventilation or death within 30 days after admission.

Conclusion Our findings support the safety and efficacy of $\mathrm{HBO}_{2}$ in the treatment of COVID-19 and severe hypoxaemia.

Trial registration number NCT04477954.

\section{INTRODUCTION}

The COVID-19 pandemic triggered a public health crisis worldwide. The most problematic clinical features of this disease are hypoxaemia and systemic

\section{Key messages}

What is already known on this subject

- Hypoxaemia in COVID-19 has a pathophysiology not yet fully understood. Many patients have required invasive and expensive treatments for hypoxaemia. Limited literature has suggested that hyperbaric oxygen is a safe and effective oxygenation method for patients with COVID-19, but well-designed studies are needed.

- Prior case studies and non-randomised clinical trials have suggested the utility of hyperbaric oxygen for hospitalised patients with COVID-19.

What this study adds

- In this multicentre randomised controlled trial of hyperbaric oxygen therapy at 1.45 atmospheres of pressure among patients with COVID-19, hypoxia was resolved in significantly shorter time in those receiving $\mathrm{HBO}_{2}$ therapy than control patients.

- Findings suggest hyperbaric oxygen is safe and effective in the treatment of severe hypoxaemia in patients with COVID-19.

hypoxia, produced by ventilation-perfusion mismatch and alveolar inflammation. ${ }^{1}$ Hypoxaemia has been independently associated with in-hospital mortality in patients with COVID-19; in moderate to critically ill patients, oxygen saturation $\left(\mathrm{SpO}_{2}\right)$ of more than $90 \%$ with oxygen supplementation indicate a very high likelihood of survival, while values below 90\%, despite normobaric oxygen supplementation, have been associated with a high mortality risk. ${ }^{2}$ Impaired oxygen diffusion leads to a drop in oxygen levels, which produces hypoxaemia and further inflammation. ${ }^{3-5}$ In severe pneumonia caused by COVID-19, impaired oxygen diffusion leads to hypoxaemia and lower level of oxygenhaemoglobin saturation. ${ }^{3-5}$

Oxygen administrated at higher pressure increases the partial pressure of oxygen in the haematoalveolar exchange, increasing gas diffusion through an altered alveolar membrane which, under the hyperbaric environment, produces a larger amount of 
dissolved oxygen in plasma and tissues. ${ }^{6}$ Moreover, hyperbaric hyperoxia has been associated with reduction of the inflammatory response. ${ }^{7}$ Hypoxaemia correction and hyperoxia generation could trigger an anti-inflammatory effect that, in turn, could lead to a clinical improvement in patients with hypoxaemic severe pneumonia associated with COVID-19. ${ }^{58}$ In case studies, $\mathrm{HBO}_{2}$ therapy has proved to be effective and safe in patients with COVID-19 pneumonia. ${ }^{9}{ }^{10}$ In patients that received $\mathrm{HBO}_{2}$ therapy, $\mathrm{SpO}_{2}$ increased, tachypnoea resolved and inflammatory markers decreased. ${ }^{10}{ }^{11}$ Randomised controlled trials investigating $\mathrm{HBO}_{2}$ therapy in patients with COVID-19 have not been published so far.

When receiving $\mathrm{HBO}_{2}$ treatment, patients breathe oxygen inside a chamber at a pressure higher than the atmospheric pressure at sea level; for clinical use, pressure is usually greater than 1.45 ATA. $^{12} \mathrm{HBO}_{2}$ therapy at medium pressure (below 2 ATA) has shown that it is neurologically safer than treatment at higher pressures. ${ }^{12-15}$ However, as the increased pressure of $\mathrm{HBO}_{2}$ therapy may exacerbate an acute lung injury or induce pulmonary oedema among patients with COVID-19, potential complications must be assessed. ${ }^{11}$ The objective of this study was to analyse the safety and efficacy of $\mathrm{HBO}_{2}$ treatment in patients with COVID-19 with severe hypoxaemia in the reduction of time for recovery from hypoxaemia (defined as $\mathrm{SatO}_{2} \leq 93 \%$ ). Also, the study evaluated if $\mathrm{HBO}_{2}$ treatment decreased progression to respiratory distress, mechanical ventilation requirements and mortality.

\section{MATERIALS AND METHODS}

This was a multicentre randomised controlled clinical trial of patients with COVID-19 performed at three public hospitals in Buenos Aires, Argentina. When the study was registered, two patients had been enrolled.

\section{Sample size calculation}

A sample size of 80 patients ( 40 in each group) was calculated with a reduction of at least $60 \%$ in the time needed to reach $\mathrm{SpO}_{2}$ of $93 \%$ (with the app epi https://www.openepi.com/SampleSize/SSCohort.htm). The sample size was based on a reduction of $\geq 60 \%$ in the time needed to reach $\mathrm{Sp}_{2}$ of $93 \%$, using an alpha error of $0.05 \%$ and $80 \%$ power. This gave a sample size of 80 patients, 40 in each group.

\section{Patient selection}

Inclusion criteria were as follows: patients in emergency department (ED) or intensive care unit, over 18 years of age (all sexes), with confirmed diagnosis of COVID-19 by PCR on nasal swab, with pneumonia with oxygen dependence (defined as the need for continuous oxygen supply to maintain pulse oximetry saturation, $\mathrm{SpO}_{2} \geq 93 \%$ or arterial gas with $\mathrm{PaO}_{2} \geq 60 \mathrm{~mm} \mathrm{Hg}$ ) and no previous hospitalisation within the last 6 months. Exclusion criteria were as follows: patients unable to give consent, were pregnant or breast feeding, required mechanical ventilation, were unable to maintain prolonged sitting position ( $\geq 2$ hours) or had contraindications for $\mathrm{HBO}_{2}$ therapy (such as acute respiratory distress syndrome (ARDS), emphysema, air cysts or bullae and untreated pneumothorax, or severe chronic obstructive pulmonary disease).

\section{Treatment}

All patients were treated following the latest guidelines of the National Ministry of Health of Argentina. ${ }^{16}$ Standard treatment for COVID-19 consisted of supportive treatment, regular antimicrobial treatment for severe community-acquired pneumonia (ceftriaxone $2 \mathrm{~g} /$ day and azithromycin $500 \mathrm{mg}$ /day for 7 days), dexamethasone $8 \mathrm{mg} /$ day, paracetamol $1 \mathrm{~g} / 6$ hours in case of high temperature and monitoring for complications. Oxygen was supplied with a reservoir mask.

\section{Procedures}

Participants were randomly assigned to receive either $\mathrm{HBO}_{2}$ treatment in addition to the standard treatment (treatment group) or the standard treatment alone (control group) for respiratory symptoms. We used simple randomisation with number assignment by a random number generator (UX App) from 1 to 10 and entered into tables assigning odd or even number to treatment or control.

$\mathrm{HBO}_{2}$ treatment consisted of $\geq 5$ sessions of $90 \mathrm{~min}$ of hyperbaric oxygen therapy administered once daily using Revitalair technology (1.45 ATA) with an inspired fraction close to $100 \%$ of oxygen. As preventive measures, chambers were cleaned with a disinfectant with quaternary ammonium salts between patients and patients, and operators wore personal protection equipment when patients were transferred to the treatment room. The regimen of $\geq 5$ sessions was chosen based on clinical experience with patients with hypoxaemia associated with COVID19. ${ }^{10}$ However, if hypoxaemia was resolved with fewer sessions, that patient would not receive more sessions and would not be included in the study; this did not occur.

The choice of equipment with pressure at 1.45 ATA was based on multiple benefits: reduced possibility of lung injury, lower cost of the equipment (therefore higher possibility of meeting the demand), ease of installation (important in the context of the pandemic), the possibility of transporting the equipment and ease of operation and disinfection. ${ }^{12} 1315$

Prior to and after each treatment, $\mathrm{SpO}_{2}$ evaluation was performed by removing the patient's oxygen mask and allowing them to breathe room air for $\geq 5$ min while monitoring $\mathrm{SpO}_{2}$ with a pulse oximeter finger probe. For patients in the control group, $\mathrm{SpO}_{2}$ on room air was monitored three times per day, every 8 hours, and the morning measure was used in the study. A fractional inspired oxyge of $21 \%$ was used to define room air.

\section{Outcomes}

Primary outcomes were proportion of patients that recovered from hypoxaemia and at 3,5 and 10 days (to assess if patient recovered after two and five sessions) and median time to recovery within 30 days. Normalisation of oxygen requirement (oxygen independence) was defined as pulse oximetry value in ambient air $\geq 93 \%$ and/or arterial blood gas with a partial pressure of oxygen $\left(\mathrm{PaO}_{2}\right)$ value of $\geq 60 \mathrm{~mm} \mathrm{Hg}$ in ambient air. Secondary outcomes were the need for mechanical respiratory assistance, development of ARDS and mortality within 30 days. Adverse events related to $\mathrm{HBO}_{2}$ therapy were recorded, including the presence of ear pain, ear obstruction, significant and constant changes in BP after 4 hours of treatment and HR, barotrauma or other symptoms.

\section{Ethical considerations}

All participants provided written informed consent, while all procedures were conducted in accordance with the principles of the World Medical Association Declaration of Helsinki. This study was carried out in compliance with Good Clinical Practice (GCP); personal data were protected and encrypted. Also, a programme of quality monitoring was performed during the clinical trial to adhere to GCP. 


\section{Patient and public involvement}

No patient involved.

\section{Statistics}

Data were analysed with an intention-to-treat approach. Categorical variables were analysed with bivariate analysis using $\chi^{2}$ test, or Fischer's test and described in percentages with 95\% CIs. Continuous variables were analysed with Student's t-test and or paired $t$ test, as appropriate and described using mean and SD or median with IQR, as appropriate, depending on distribution and analysis with Shapiro-Wilk test. Inferential analyses were performed using a bivariate analysis by calculating adjusted OR with 95\% CIs and adjusted OR with a multiple logistic regression model. HRs were used for time to event. Log rank test and Cox regression were used to calculate HR, controlling for age, sex, arterial hypertension, obesity, diabetes, smoking and COPD. Statistical significance was set at $p<0.05$. Statistical analyses were performed with Stata V.13.0.

\section{Planned interim analysis}

An interim analysis of the results was scheduled once $50 \%$ of the patients were recruited. An independent investigator presented a report of the analysis to the hospitals' ethics committee, and this authorised the early suspension of the study. Analysis was prespecified in the original protocol; outcomes were the proportion of recovery from hypoxaemia and at 3, 5 and 10 days and time to correct hypoxaemia. Following the methodology presented by Pocock, ${ }^{17}$ the $\mathrm{p}$ values for the interim analysis and the criteria to stop the trial based on clinical benefits were reported with adjusted error type I at 0.0294 .

\section{RESULTS}

From July to November 2020, 40 patients were included. The study was stopped at interim analysis; analysis occurred after enrolment. The study was interrupted with the approval of each independent ethics committee when interim analysis with 50\% of sample size showed a marked benefit of treatment. To that point, the cohort was as follows: $20(50.0 \%)$ were assigned to $\mathrm{HBO}_{2}$ treatment group and $20(50.0 \%)$ to the control group. Of the 40 randomised, 39 completed the protocol $\left(19\right.$ in $\mathrm{HBO}_{2}$ group and 20 in the control group). One patient in the $\mathrm{HBO}_{2}$ withdrew after the second session because of ear discomfort (figure 1).

Mean age was 55.2 \pm 9.2 years, and $26(65.0 \%)$ patients were male. Demographic and clinical characteristics are shown in table 1. Baseline demographics and clinical variables between the two groups were comparable (table 1). Baseline $\mathrm{SpO}_{2}$ was $85.1 \% \pm 4.3 \%$ for the whole group, $86.5 \% \pm 3.9 \%$ in the treatment group and $84.1 \% \pm 4.5 \%$ in the control group, with no significant difference between the two groups $(p=0.150)$ (table 2).

Four $(10.0 \%)$ of 40 patients had a poor clinical course (composite outcome of acute respiratory distress syndrome, mechanical ventilation requirements or death) within 30 days of admission, with $3(15.0 \%)$ patients in the control group and $1(5.0 \%)$ patient in the treatment group, with no statistically significant difference. Two (5.0\%) patients died within 30 days after admission, one in each group. The use of $\mathrm{HBO}_{2}$ treatment had no statistically significant effect on the incidence of ARDS, mechanical ventilation or death within 30 days after admission (table 2).

Patients included in the treatment group $(n=20)$, including the patient who abandoned treatment, received an average of

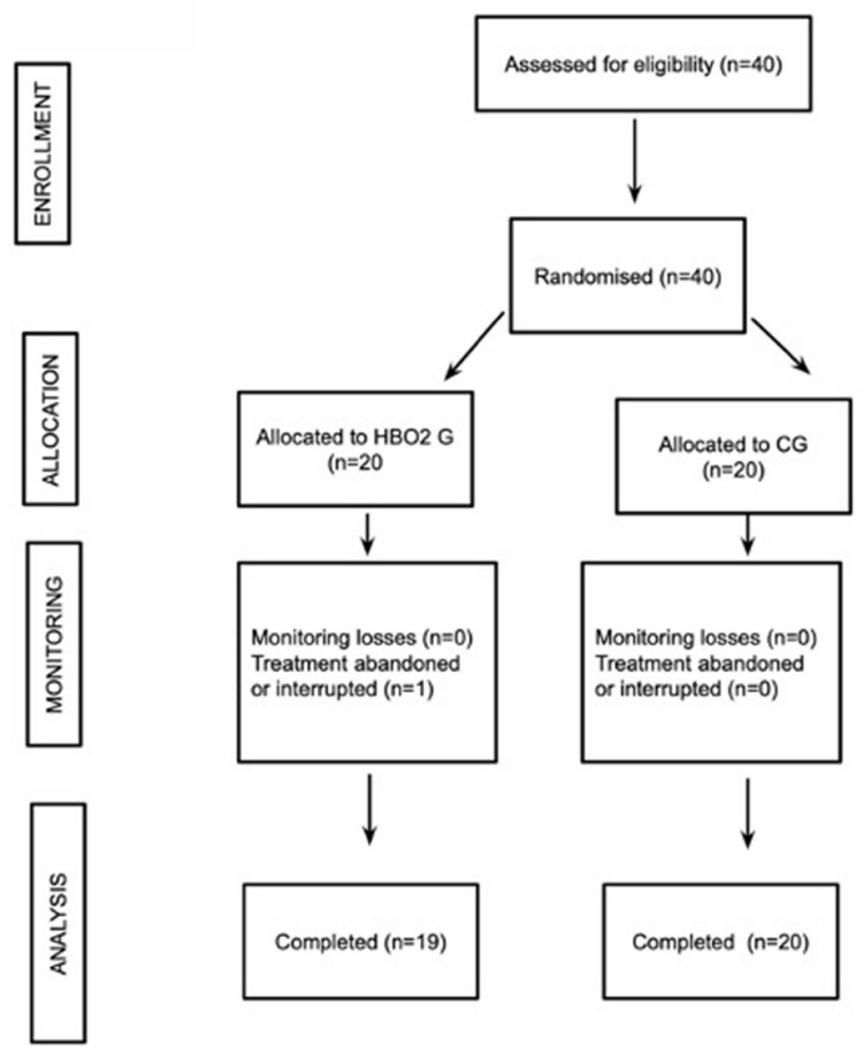

Figure 1 Flow chart of included patients. CG, control group; $\mathrm{HBO}_{2}$, hyperbaric oxygen treatment group.

$6.2 \pm 1.2$ hyperbaric oxygen sessions. The difference between arterial saturation at pre- $\mathrm{HBO}_{2}$ and post- $\mathrm{HBO}_{2}$ treatment session was significant for most sessions (table 3 ). $\mathrm{SpO}_{2}$ showed an immediate and successive daily improvement at a higher slope compared with the patients who did not receive $\mathrm{HBO}_{2}$ (table 3 and figure 2).

Hypoxaemia correction (defined as $\mathrm{SpO}_{2} \geq 93 \%$ ) was reached in the $\mathrm{HBO}_{2}$ treatment group, with a greater upward slope of arterial saturation compared with control group. Time to correct hypoxaemia was shorter in the treatment group compared with the control group: median (IQR) 3 (1.0-4.5) days versus 9 (5.5$12.5)$ days, respectively $(\mathrm{p}<0.010), \log$ rank $\chi^{2} 28.31, \mathrm{p}<0.001$; HR 6.9 (95\% CI 2.9 to 16.2); adjusted HR was 7.7 (95\% CI 3.1 to 19.5$)(\mathrm{z} 4,3 \mathrm{p}<0.001)$. The OR of recovery from hypoxaemia in the $\mathrm{HBO}_{2}$ group compared with the control group was 23.2 (95\% CI 1.6 to $329.6 ; \mathrm{p}=0.001)$ at day 3 and 28.5 (95\% CI 1.8 to $447.4 ; \mathrm{p}<0.001$ ) at day 5 (table 2 ). Figure 3 shows computed tomography (CT) images of two patients at the beginning of $\mathrm{HBO}_{2}$ treatment (figure $3 \mathrm{~A}$ ) and after receiving five sessions (figure $3 \mathrm{~B}$ ) and one patient in the control group at day 1 and 20 days later (figure $3 \mathrm{C}$ ).

\section{DISCUSSION}

Our findings suggest that supplementing oxygen through $\mathrm{HBO}_{2}$ treatment contributed to an increased $\mathrm{SpO}_{2}$ in patients with COVID-19 with severe hypoxaemia, with no significant adverse effects. Cases of severe COVID-19 that need mechanical ventilation have a high mortality risk. Therefore, novel therapeutic strategies are needed, and this study offers evidence supporting $\mathrm{HBO}_{2}$ treatment . Even in the context of the ED, a small number 
Table 1 Demographic and clinical characteristics

\begin{tabular}{|c|c|c|c|}
\hline Characteristic & Total, $n=40$ & $\mathrm{HBO}_{2}, \mathrm{n}=20$ & Control, $n=20$ \\
\hline Male, n (\%) & $26(65)$ & $13(65)$ & $13(65)$ \\
\hline Age, years* & $55.2 \pm 9.2$ & $52.8 \pm 8.5$ & $57.7 \pm 9.3$ \\
\hline Weight, kg† & $82.0(90.0 ; 75.0)$ & $79.5(74.0 ; 90.0)$ & $86.0(79.0 ; 100.0)$ \\
\hline Height, $\mathrm{cm} \dagger$ & $172.5(169.5 ; 179.0)$ & $171.0(169.5 ; 174.0)$ & $175.0(170.5 ; 179.5)$ \\
\hline $\mathrm{BMI}, \mathrm{kg} / \mathrm{m}^{2} \dagger$ & $27.7(25.1 ; 30.3)$ & $27.9(24.7 ; 29.0)$ & $27.2(25.8 ; 32.1)$ \\
\hline $\mathrm{SAP}, \mathrm{mm} \mathrm{Hg}{ }^{\dagger}$ & $120.0(120.0 ; 130.0)$ & $120.0(115.0 ; 127.5)$ & $125.0(120.0 ; 130.0)$ \\
\hline $\mathrm{DAP}, \mathrm{mm} \mathrm{Hg}{ }^{*}$ & $77.8 \pm 10.4$ & $75.9 \pm 10.7$ & $79.7 \pm 9.9$ \\
\hline $\mathrm{HR}, \mathrm{bpm}^{*}$ & $88.8 \pm 13.4$ & $85.9 \pm 14.6$ & $91.7 \pm 11.7$ \\
\hline Respiratory rate, rpm* & $26.4 \pm 4.6$ & $25.3 \pm 0.9$ & $27.4 \pm 1.0$ \\
\hline Temperature, ${ }^{\circ} \mathrm{C} \dagger$ & $36.7(36.4 ; 37.0)$ & $36.8(36.4 ; 37.2)$ & $36.7(36.4 ; 36.8)$ \\
\hline Haematocrit \%* & $38.3 \pm 4.8$ & $39 \pm 3,99$ & $37.7 \pm 5.4$ \\
\hline White cell count, $/ \mathrm{mm}^{3}$ * & $9,008 \pm 3456$ & $9,214 \pm 3209$ & $8,803 \pm 3758$ \\
\hline Lymphocytes, /mm $3 *$ & $1,319 \pm 489$ & $1,403 \pm 563$ & $1,245 \pm 415$ \\
\hline Platelets, $\times 1000 / \mathrm{mm}^{3} \dagger$ & $281.5(212.0 ; 352.5)$ & $299.5(268.1-372.0)$ & $268.0(105.5 ; 310.0)$ \\
\hline Blood glucose, mg/dL† & $109.0(99.0 ; 119.5)$ & $109.0(101.5 ; 115.5)$ & $107.0(97.0 ; 199.5)$ \\
\hline Urea, mg/dL† & $39.0(26.0 ; 46.0)$ & $34.0(24.0 ; 46.0)$ & $40.5(32.4 ; 45.5)$ \\
\hline Creatinine, mg/dLt & $0.88(0.7 ; 1.1)$ & $0.9(0.7 ; 1.0)$ & $0.9(0.7 ; 1.1)$ \\
\hline Sodium, $\mathrm{mEq} / \mathrm{L}^{*}$ & $136.4 \pm 4.8$ & $136.7 \pm 3.2$ & $136.4 \pm 4.8$ \\
\hline Potassium, $\mathrm{mEq} / \mathrm{L}^{*}$ & $4.0 \pm 0.4$ & $3.9 \pm 0.4$ & $4.0 \pm 0.3$ \\
\hline \multicolumn{4}{|l|}{ Comorbidity } \\
\hline Obesity, n (\%) & $14(35.0)$ & $6(30.0)$ & $8(40.0)$ \\
\hline Hypertension, n (\%) & $13(32.5)$ & $8(40.0)$ & $5(25.0)$ \\
\hline Diabetes, n (\%) & $7(17.5)$ & $3(15.0)$ & $4(20.0)$ \\
\hline COPD, n (\%), & $2(5.0)$ & $0(0.0)$ & $2(10.0)$ \\
\hline Asthma, n (\%) & $2(5.0)$ & $2(10.0)$ & $0(0.0)$ \\
\hline CKD, n (\%) & $2(5.0)$ & $1(5.0)$ & $1(5.0)$ \\
\hline Cancer, n (\%) & $2(5.0)$ & $0(0.0)$ & $2(10.0)$ \\
\hline \multicolumn{4}{|l|}{ Symptoms, n (\%) } \\
\hline Fever & 35 (87.5) & $17(85.0)$ & $18(90.0)$ \\
\hline Odynophagia & $17(42.5)$ & $10(50.0)$ & $7(35.0)$ \\
\hline Anosmia & $6(15.0)$ & $4(20.0)$ & $2(10.0)$ \\
\hline Dysgeusia & $7(17.5)$ & $4(20.0)$ & $3(15.0)$ \\
\hline Dyspnoea & $37(92.5)$ & $19(95.0)$ & $18(90.0)$ \\
\hline Headache & $4(10.0)$ & $2(10.0)$ & $2(10.0)$ \\
\hline
\end{tabular}

Data are described as

*mean \pm SD.

tmedian (IQR)

BMI, body mass index; bpm, beats per minute; CKD, chronic kidney disease; COPD, chronic obstructive pulmonary disease; DAP, diastolic arterial pressure; rpm, rate per minute; SAP, systolic arterial pressure.

of $\mathrm{HBO}_{2}$ sessions, as shown in our findings, could benefit patients before they are transferred to intensive care.

Dyspnoea and hypoxaemia $\left(\mathrm{SpO}_{2}<90 \%\right.$ despite oxygen supplementation) have been added to a list of risk factors for mortality in patients with COVID-19 pneumonia, together with age, sex, comorbidities and inflammatory biomarkers. ${ }^{2}$ In severe cases of COVID-19, there occurs an acute lung injury, macrophage-neutrophil accumulation in the lungs and elevated proinflammatory serum cytokines. ${ }^{18} \mathrm{HBO}_{2}$ treatment involves the increasing partial pressure of oxygen in plasma and tissues, with improved diffusion efficiency of oxygen through the alveolar barrier, a higher content of dissolved oxygen in the blood and increased diffusion distance of oxygen. ${ }^{6} \mathrm{HBO}_{2}$ treatment may modulate the inflammatory response and the cytokine level,

Table 2 Outcomes within 30 days of diagnosis

\begin{tabular}{|c|c|c|c|c|c|}
\hline Outcomes & Total $(n=40)$ & $\begin{array}{l}\mathrm{HBO}_{2} \\
(\mathrm{n}=20)\end{array}$ & Control $(n=20)$ & $P$ value & Effect size $(95 \% \mathrm{Cl})$ \\
\hline Days to normalisation* & $5.0(3.0 ; 9.0)$ & $3.0(1.0 ; 4.5)$ & $9.0(5.5 ; 12.5)$ & $<0.010$ & HR 6.9 (2.9 to 16.2$)$ \\
\hline $\mathrm{SpO}_{2} \geq 93 \%$ at 3 days, $\mathrm{n}(\%)$ & $12(30)$ & $11(55)$ & $1(8)$ & 0.001 & OR 23.2 (1.6 to 329.6) \\
\hline $\mathrm{SpO}_{2} \geq 93 \%$ at 5 days, $\mathrm{n}(\%)$ & $27(68)$ & $19(95)$ & $8(40)$ & $<0.001$ & OR 28.5 (1.8 to 447.4 ) \\
\hline $\mathrm{SpO}_{2} \geq 93 \%$ at 10 days, $\mathrm{n}(\%)$ & $33(83)$ & $20(100)$ & $13(65)$ & 0.004 & $\infty$ \\
\hline $\mathrm{SpO}_{2} \geq 93 \%$ at 15 days, $\mathrm{n}(\%)$ & $36(90)$ & $20(100)$ & $16(80)$ & 0.106 & $\infty$ \\
\hline Acute respiratory distress, $\mathrm{n}(\%)$ & $4(10)$ & $1(5)$ & $3(15)$ & 0.605 & OR 0.3 (0.0 to 3.4 ) \\
\hline Mechanical ventilation, $\mathrm{n}(\%)$ & $4(10)$ & $1(5)$ & $3(15)$ & 0.605 & OR 0.3 (0.0 to 3.4 ) \\
\hline Death, n (\%) & $2(5)$ & $1(5)$ & $1(5)$ & 1.000 & OR 1.0 (0.1 to 17.8$)$ \\
\hline
\end{tabular}

* Median (25th percentile; 75th percentile).

$\mathrm{SpO}_{2}$, oxygen saturation. 


\begin{tabular}{|c|c|c|c|c|}
\hline Saturation assessment & Total $(n=40)$ & $\mathrm{HBO}_{2}(\mathrm{n}=20)$ & Control $(n=20)$ & $P$ value \\
\hline $\mathrm{SpO}_{2}$ on day $1, \% *$ & $85.1 \pm 4.3$ & $86.5 \pm 3.9$ & $84.1 \pm 4.5$ & 0.150 \\
\hline $\mathrm{SpO}_{2}$ on day $2, \% *$ & $86.7 \pm 4.6$ & $89.0 \pm 4.1$ & $84.4 \pm 3.9$ & $<0.010 \neq$ \\
\hline $\mathrm{SpO}_{2}$, on day $3, \%^{*}$ & $87.9 \pm 3.1$ & $89.6 \pm 2.8$ & $86.4 \pm 2.5$ & $<0.010 \neq$ \\
\hline $\mathrm{SpO}_{2}$ on day $4, \% \dagger$ & $89.0(88.0 ; 92.0)$ & $93.0(91.0 ; 94.0)$ & $88.0(82.0 ; 89.0)$ & $<0.010 \neq$ \\
\hline $\mathrm{SpO}_{2}$ on day $5, \% \dagger$ & $91.0(88.0 ; 93.0)$ & $93.0(92.0 ; 95.0)$ & $88.0(87.0 ; 91.0)$ & $<0.010 \neq$ \\
\hline $\mathrm{SpO}_{2}$ on day $6, \% \dagger$ & $93.0(89.0 ; 94.0)$ & $94.0(93.5 ; 95.5)$ & $90.0(88.0 ; 92.0)$ & $<0.010 \ddagger$ \\
\hline $\mathrm{SpO}_{2}$ on day $7, \% \dagger$ & $92.0(90.0 ; 94.0)$ & $94.0(93.0 ; 95.0)$ & $91.0(89.5 ; 92.0)$ & $0.020 \ddagger$ \\
\hline
\end{tabular}

Data are described as

*mean \pm SD.

tmedian (IQR).

¥Statistically significant.

$\mathrm{SpO}_{2}$, oxygen saturation.

appearing to increase FGF production and collagen synthesis and decrease interleukin 1, interleukin 6 and tumour necrosis alpha factor; also, it has been suggested that the treatment may affect the expression levels of transforming growth factor beta-1 and platelet-derived growth factor. ${ }^{619-21}$ Moreover, COVID-19 related stressors exacerbate the effects of the disease by inducing the generation of oxidative stress, affecting the host's immune response and associated with systemic tissue damage. ${ }^{22} \mathrm{HBO}_{2}$ treatment below 2.0 ATA increases the activity of antioxidant enzymes, including first-line defence antioxidants superoxide dismutase and catalase. ${ }^{11}$

Case series have reported that patients with COVID-19 treated with $\mathrm{HBO}_{2}$ showed improved survival and could avoid mechanical ventilation. ${ }^{7}$ Our findings support case series suggesting the beneficial effect of $\mathrm{HBO}_{2}$ in the correction of hypoxaemia. In case series, as suggested by Paganini et $\mathrm{al}^{7}$, it is not possible to determine if improved outcomes were the effect of the treatment or time. Comparing our two groups, the effect of $\mathrm{HBO}_{2}$ seems to be significantly more beneficial than receiving no treatment.

We acknowledge that this study has limitations. The interim analysis and early suspension because of clinical benefits (superiority and safety) should be taken into account; this limited conclusions about the secondary outcomes. Indeed, the small number of patients included in the study is an important limitation. Although not statistically significant, there is a trend towards younger patients in the treatment group. Also, data were acquired under emergency conditions; so, information on some variables could not be included, for example, baseline oxygen requirement. However, only patients with requirement

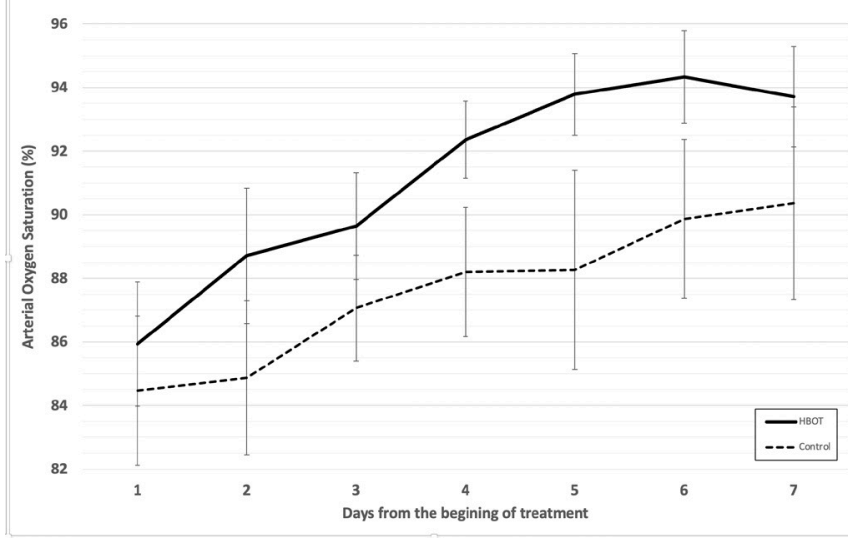

Figure 2 Improvement of arterial oxygen saturation over the course of treatment.
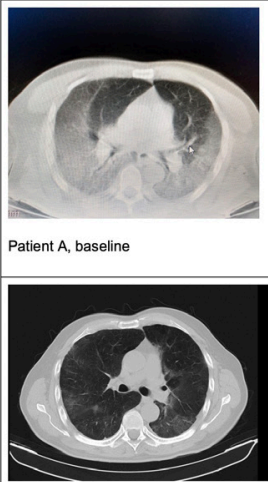

Patient $A$, after 5 sessions of treatment

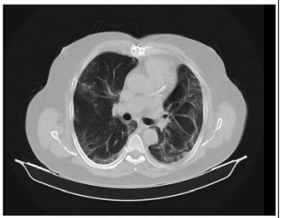

Patient B, baseline

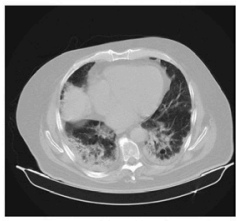

Patient C (control), baseline

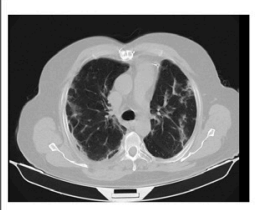

Patient $B$, after 5 sessions of treatment

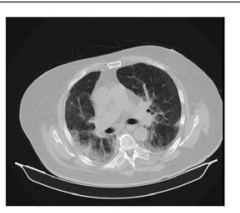

Patient $\mathrm{C}$ (control), after 20 days

Figure $3 \mathrm{CT}$ images of patients. Patients in treatment group ( $\mathrm{A}$ and $\mathrm{B}$ ) and patient in control group (C).

of high-flow oxygen were included. It was not possible to determine the moment hypoxaemia had been established, and $\mathrm{HBO}_{2}$ could have been more effective in reducing mortality when hypoxaemia was recently established. Normalisation of oxygen was selected as the primary outcome because long-term hyperpoxia induces more residual multisystemic inflammatory complications. $^{2}$ In fact, mortality depends on many other variables that could not be controlled in this study, such as previous days of hypoxaemia.

This treatment could be easily available in various settings. Portable hyperbaric chambers offer a fast setup to avoid transferring patients to other hospital areas, attenuating the risk of virus transmission. In conclusion, our findings support the efficacy of $\mathrm{HBO}_{2}$ in the treatment of COVID-19 with severe hypoxaemia; larger trials are needed to further confirm the treatment effects on survival.

\footnotetext{
Author affiliations

${ }^{1}$ Research Department, Argentine Association of Hyperbaric Medicine and Research (AAMHEI), Buenos Aires, Argentina

${ }^{2}$ Laboratory of Arterial Hypertension, Cardiology Department, Hospital de Clinicas Jose de San Martin, Buenos Aires, Argentina

${ }^{3}$ Segunda Cátedra de Fisiología, Universidad de Buenos Aires Facultad de Medicina, Buenos Aires, Argentina

${ }^{4}$ Instituto Alberto C Taquini de Investigaciones en Medicina Traslacional - Facultad de Medicina, Universidad de Buenos Aires and CONICET, Buenos Aires, Argentina ${ }^{5}$ General Medicine, Hospital General de Agudos Donación Santojanni, Buenos Aires, Federal District, Argentina

${ }^{6}$ Tercera Cátedra de Farmacología, Facultad de Medicina, Universidad de Buenos Aires, Buenos Aires, Argentina

${ }^{7}$ General Medicine, Municipal Hospital of San Isidro, San Isidro, Argentina
} 
${ }^{8}$ Intensive Care Unit, Hospital de Infecciosas Dr Francisco Javier Muñiz, Buenos Aires, Argentina

${ }^{9}$ Qualitative Research in Health, Institute for Clinical Effectiveness and Health Policy, Buenos Aires, Argentina

${ }^{10}$ Centre for Research on Epidemiology and Public Health (CIESP), CONICET, Buenos Aires, Argentina

${ }^{11}$ Hyperbaric Medicine, Hospital Alta Complejidad JD Perón, Formosa, Argentina

Acknowledgements The authors would like to thank Ms Pilar Maria Emilia Fraga for quality monitorisation of the present study.

Contributors Concept: MC, GK and EE. Design: MC, GK, LJ-V and DM. Data collection: MD, GK, RL, EC, VC, MM, DMB, EG, HEDS, FV, CD and GDG. Data analysis: $M C, M D, G K, ~ L J-V$ and EE. Visualisation: LJ-V and JR. Interpretation: MC, MD, GK, RL, DMB, HEDS, FV, LJ-V, GDG, JR and EE. Investigation: MC, MD, GK, LJ-V, JR and EE. Draft writing: LJV, MC and JR. Guarantor: MC. All authors reviewed and commented the manuscript.

Funding The authors have not declared a specific grant for this research from any funding agency in the public, commercial or not-for-profit sectors.

Competing interests $M C$ is medical director, FV is medical liaison and $\mathrm{LJ}-\mathrm{V}$ is scientific director and management in clinical research of Biobarica Hyperbaric Medical Centers Net.

Patient and public involvement Patients and/or the public were not involved in the design, or conduct, or reporting, or dissemination plans of this research.

Patient consent for publication Consent obtained directly from patient(s)

Ethics approval Ethics committee of three participating hospitals: Municipal de San Isidro, Santojanni, Muñiz.

Provenance and peer review Not commissioned; externally peer reviewed.

Data availability statement Data are available on reasonable request. Additional information available on request to authors.

Open access This is an open access article distributed in accordance with the Creative Commons Attribution Non Commercial (CC BY-NC 4.0) license, which permits others to distribute, remix, adapt, build upon this work non-commercially, and license their derivative works on different terms, provided the original work is properly cited, appropriate credit is given, any changes made indicated, and the use is non-commercial. See: http://creativecommons.org/licenses/by-nc/4.0/.

\section{ORCID iDs}

Guillermo Keller http://orcid.org/0000-0003-4334-6741

Javier Roberti http://orcid.org/0000-0002-4285-5061

\section{REFERENCES}

1 Chen N, Zhou M, Dong X, et al. Epidemiological and clinical characteristics of 99 cases of 2019 novel coronavirus pneumonia in Wuhan, China: a descriptive study. Lancet 2020;395:507-13.

2 Xie J, Covassin N, Fan Z, et al. Association between hypoxemia and mortality in patients with COVID-19. Mayo Clin Proc 2020;95:1138-47.
3 Tobin MJ, Laghi F, Jubran A. Why COVID-19 silent hypoxemia is Baffling to physicians. Am J Respir Crit Care Med 2020;202:356-60.

4 Cavezzi A, Troiani E, Corrao S. COVID-19: hemoglobin, iron, and hypoxia beyond inflammation. A narrative review. Clin Pract 2020;10:24-30.

5 Solaimanzadeh I. Heterogeneous perfusion in COVID-19 and high altitude pulmonary edema: a review of two cases followed by implications for hypoxic pulmonary vasoconstriction, thrombosis development, ventilation perfusion mismatch and emergence of treatment approaches. Cureus 2020:12:e10230.

6 Choudhury R. Hypoxia and hyperbaric oxygen therapy: a review. Int I Gen Med 2018;11:431-42.

7 Paganini M, Bosco G, Perozzo FAG, et al. The role of hyperbaric oxygen treatment for COVID-19: a review. Adv Exp Med Biol 2021;1289:27-35.

8 Geier MR, Geier DA. Respiratory conditions in coronavirus disease 2019 (COVID-19): important considerations regarding novel treatment strategies to reduce mortality. Med Hypotheses 2020;140:109760.

9 Gattinoni L, Chiumello D, Caironi P, et al. COVID-19 pneumonia: different respiratory treatments for different phenotypes? Intensive Care Med 2020:46:1099-102.

10 Thibodeaux K, Speyrer M, Raza A, et al. Hyperbaric oxygen therapy in preventing mechanical ventilation in COVID-19 patients: a retrospective case series. J Wound Care 2020:29:54-8.

11 Gorenstein SA, Castellano ML, Slone ES, et al. Hyperbaric oxygen therapy for COVID-19 patients with respiratory distress: treated cases versus propensity-matched controls. Undersea Hyperb Med 2020;47:405-13.

12 Kot J, Winklewski PJ, Sicko Z, et al. Effect of oxygen on neuronal excitability measured by critical flicker fusion frequency is dose dependent. $J$ Clin Exp Neuropsychol 2015:37:276-84

13 Efrati S, Ben-Jacob E. Reflections on the neurotherapeutic effects of hyperbaric oxygen. Expert Rev Neurother 2014;14:233-6.

14 Shah J. Hyperbaric oxygen therapy. J Am Col Certif Wound Spec 2010;2:9-13.

15 Cannellotto M, Romero-Feris D, Pascuccio MM, et al. Aplicaciones médicas de las cámaras de oxigenación hiperbárica de nueva generación. Asoc Med Arg 2018;131:12-20

16 National Ministry of Health of Argentina. Recomendaciones para el abordaje terapéutico de COVID-19. Buenos Aires, Argentina, 2020.

17 Pocock SJ. Group sequential methods in the design and analysis of clinical trials. Biometrika 1977;64:191-9.

18 Conti P, Ronconi G, Caraffa A, et al. Induction of pro-inflammatory cytokines (IL-1 and IL-6) and lung inflammation by Coronavirus-19 (COVI-19 or SARS-CoV-2): antiinflammatory strategies. J Biol Regul Homeost Agents 2020;34:327-31.

19 Strauss MB, Bryant BJ, Hart GB. Transcutaneous oxygen measurements under hyperbaric oxygen conditions as a predictor for healing of problem wounds. Foot Ankle Int 2002:23:933-7.

20 Rockswold SB, Rockswold GL, Zaun DA, et al. A prospective, randomized clinical trial to compare the effect of hyperbaric to normobaric hyperoxia on cerebral metabolism, intracranial pressure, and oxygen toxicity in severe traumatic brain injury. J Neurosurg 2010:112:1080-94

21 Al-Waili NS, Butler GJ. Effects of hyperbaric oxygen on inflammatory response to wound and trauma: possible mechanism of action. ScientificWorldJournal 2006;6:425-41.

22 Bakadia BM, Boni BOO, Ahmed AAQ, et al. The impact of oxidative stress damage induced by the environmental stressors on COVID-19. Life Sci 2021;264:118653. 